\title{
Enriching Intellectual Discourse with Overseas Study and Work
}

As a student at Boston College, and now in his current graduate work, Kevin McAdam has shown a long-term and fundamental interest in integrating overseas experience and research into his formal academic program. This is a specific and extremely high priority of Boston College with respect to all its foreign study programs. Indeed, BC has investigated the approaches of other universities nationwide and determined how to strategically approach this crucial element of the undergraduate experience. We seek to fully, formally, and early identify the overseas university programs of most value to our students' academic plans, and to encourage them to apply. In Kevin's case, his International Studies major program is a leader on campus in this regard, and several of his primary BC professors have been central to executing this approach to foreign study. Kevin showed a deep commitment to research, writing, and public service related to the major public policy challenges confronting developing and least developed countries. As an undergraduate, for example, he assisted in the design and execution of an environmental awareness program in India and the construction of water wells in northern Kenya.

At $\mathrm{BC}$, responding directly to his experience overseas, he established a Latin American trade and development program. He was genuinely and deeply committed to understanding through overseas classroom and volunteer experience the nature of cultural, social, political, and economic change in least developed countries. He very carefully pursued his academic program and selected his courses in order to complete the most challenging and relevant courses not only at BC but also through his foreign study program and internship in Geneva. He drew heavily on both his foreign study courses and research papers and the most relevant speaker series and related activities he completed in Geneva.

As a result of his stellar record and highly relevant foreign study experience, I invited him to work as an Arts \& Sciences Faculty-Undergraduate Research Fellow with me the summer after he studied abroad. Once selected for the reward, we worked closely on specific elements of my own research project on public policy and economic reform in developing countries. He dedicated substantial time to analyzing data and research that spanned my project and his main research interests. He performed very useful analysis and 
writing toward my forthcoming book. I was particularly impressed by his capability for independent work, his keen insight and ability to isolate critical questions and trends, and his seriousness of purpose with research questions well beyond those encountered in his regular academic curriculum.

Based on his unusually impressive intellectual record at BC, overseas foreign study performance, and his work for me during the summer, Kevin was invited to compete for a position in the university's highest research honor for undergraduates - the Scholar of the College Program, which requires much more effort than the normal senior honors thesis. After presenting the results of his research and writing to a major faculty selection committee in fall, 2003, his work was judged appropriate for the Scholar Program.

The outcome is his formally completed and accepted Scholar of the College, "The Human Right to Water - Market Allocations and Subsistence in a World of Scarcity." It represents the finest case wherein the prestigious International Studies Major (the only academic major by formal application at BC), formally integrating overseas courses and experience, prepares students to grapple with deeper questions and issues which include multidisciplinary dimensions. Kevin's is one of the very best cases, a senior-year project with serious intellectual depth and theoretical questions. His Scholar Project tackles an issue of fundamental importance for human development worldwide. Furthermore, he frames the question of access to water for individuals of the least economic capacity as a fundamental question of human rights, precisely as he studied and helped to support them overseas. In so doing, he integrated subtle questions and important literatures from ethics and theology, human rights and international relations, and public policy and political economy.

Drawing on his foreign study research and writing and the most relevant and important published work in this area, Kevin formulates a coherent and persuasive case for water as a basic human right and applies this argument to an assessment of how water systems are being privatized and otherwise managed by governments in developing and least developed countries. The product is a careful but assertive confirmation of his argument that governments, public international organizations, and private sector actors are not adequately providing the basic human right of access to water at the subsistence level. Most impressive is his smooth and subtle integration of the empirical work with the conceptual framework.

Overall, this is a clear example of how foreign study should become a foundation for major senior-year projects. He has drawn on much of his academic background, his foreign research, his intellectual interests, and his professional 
experience overseas. He has grappled with a deep and fundamental issue, and mobilized substantial empirical information to test his argument.

Kevin has also developed an impressive set of skills in working with people from a wide range of different backgrounds, including especially those from foreign cultures and those with the fewest advantages or resources available to them. He has developed an unusual capacity for working intensively with people to understand and identify both what is most in need of change and how to approach the gradual implementation of even fundamental changes. Perhaps most important, he is highly sensitive to the need to view these changes as cultural and societal in the fullest and deepest sense.

Kevin's integration of overseas and US study is exemplary. As a student he is genuinely and thoughtfully committed to the goals of enriching intellectual discourse with overseas study and work. He appreciates the profound challenges posed by the cultural context of public policy and human rights in any country. His academic career is an example of the very best outcomes of overseas study integrated into the entire undergraduate experience.

\section{D a vid A. D e e s e}

Associate Professor

Department of Political Science

(former Director, International Studies Program, 1986-2002)

Boston College 